\title{
A arte de governar, vigiar e disciplinar na província do Rio Grande de São Pedro: o poder da câmara municipal da vila de Nossa Senhora do Rio Pardo e dos juízes almotacés nas primeiras décadas do século XIX
}

The art to govern, watch and disciple in the province of Rio Grande de São Pedro: Nossa Senhora do Rio Pardo village's town hall and almotacésjudges power in the first decades of the XIX century El arte de gobernar, vigilar y disciplinar en la provincia de Rio Grande de São Pedro: el poder de la cámara municipal de la villa de nuestra Señora de Rio Pardo y de los jueces almotacés en las primeras décadas del siglo XIX

Ricardo Schmachtenberg*

\section{Resumo}

Os estudos realizados a partir da década de 1990, no campo da história social e da história política, têm recorrido à documentação produzida no âmbito municipal com o objetivo de reconstituir diferentes aspectos do cotidiano da cidade. Ao abordar os problemas relacionados a questões como moradia, saúde e higiene pública e ao comércio, esses estudos têm enfatizado não só a vida cotidiana, mas também os poderes que controlam esse cotidiano, que controlam a vida e a sociedade nas vilas e nas cidades. Portanto, este texto analisa o poder e a atuação da Câmara Municipal da Vila de Nossa Senhora do Rio Pardo e dos juízes almotacés nas primeiras décadas do século XIX, como forma de regular a vida social, controlando e disciplinando os cidadãos, as atividades comerciais, a saúde e a higiene pública e as habitações, dialogando dentro de uma perspectiva pela qual se enfatiza que as câmaras municipais tinham poder de se autogovernarem e que não eram instituições meramente subordinadas aos poderes central e regional.

Palavras-chave: Arte de governar. Poder local. Câmara municipal.

\footnotetext{
Graduado em Estudos Sociais - habilitação em História, pela Universidade de Santa Cruz do Sul (2001). Mestre em História, pela Universidade do Vale do Rio dos Sinos (2004). Doutor em História, também pela Universidade do Vale do Rio dos Sinos (2012). Professor de História nos níveis fundamental e médio.
}

Recebido em 10/07/2013 Aprovado em 27/11/2013 http://dx.doi.org/10.5335/hdtv.14n.1.3327 


\section{0 poder das câmaras municipais}

Até recentemente, a historiografia brasileira dava pouca atenção aos estudos sobre a administração colonial portuguesa no Brasil e, em especial, às câmaras municipais, aos seus integrantes e aos poderes que dessa emanavam. A documentação produzida pelas câmaras municipais brasileiras durante o período colonial ainda é, por muitos, considerado "como sendo um mero reflexo da máquina administrativa do estado português, registrando apenas atos rotineiros, de pouco interesse para a história" (SANTOS; SANTOS, 2003, p. 1). Muitos trabalhos e investigações a respeito desse período e, principalmente, do estatuto político, composição e funcionamento das câmaras municipais foram feitos por investigadores e historiadores estrangeiros, como é o caso de Charles Boxer, Stuart B. Schwartz e A. John Russel-Wood (RUSSEL-WOOD, 1981; BOXER, 2002; SCHWARTZ, 2011).

Para os brasileiros, segundo Laura de Mello e Souza, “a administração era tema sem nobreza nenhuma, bem ao gosto de historiadores afeitos à tradição e ao conservadorismo, numa senda em tudo oposta à que levava ao estudo do sistema escravista ou da formação da classe operária". Prossegue a autora destacando que

[...] estudar governadores, instituições locais - câmaras municipais, irmandades, misericórdias - ou gerais - conselhos, como o Ultramarino; tribunais, como a Relação era atividade para os empoeiradíssimos Institutos Históricos, e quase inevitavelmente redundava em obras apologéticas ou encomiásticas (SOUZA, 2009, p. 65).
Porém, os estudos realizados a partir da década de 1990, no campo da história social e da história política, têm recorrido à documentação produzida no âmbito municipal com o objetivo de reconstituir diferentes aspectos do cotidiano da cidade. Ao abordar os problemas relacionados a questões como moradia, saúde e higiene pública, comércio e transações comerciais, esses estudos têm enfatizado não somente o cotidiano, mas também os poderes locais, esses vinculados, principalmente, às câmaras municipais e ao poder que essa representou, concomitantemente às práticas políticas e pretensões das elites locais.

Nesse sentido, trabalhos como o de Maria Helena Cruz Coelho explicitam a importância de se pesquisar fontes que dizem respeito ao aparelho administrativo, em especial, às câmaras. Atas de vereança, posturas, livros de receita e despesa são reinterpretados a partir de novas abordagens, assim como novos estudos sobre quem governa os municípios, bem como sobre a forma como são governados, as disputas, os conflitos e as relações de poder que se passam no íntimo camarário, na formação de facções e na atuação desses grupos junto ao soberano com a intenção de receber mercês, benesses, rendas, para se autoafirmarem perante a comunidade local. Conforme a autora, a abrangência dessas fontes leva-nos a um maior conhecimento do cotidiano das pessoas, da vida urbana, das relações sociais e de poder, da convivência, da higiene e saúde, ainda não suficientemente exploradas pelos historiadores (COELHO, 1999).

A responsabilidade de legislar e fiscalizar, assim como de discutir e decidir 
questões concernentes à vida municipal, eraespaço de competência da câmara municipal. Segundo Sérgio Cunha Soares, as atas camarárias eram a reprodução de uma voz municipal, tantas vezes divergente, que manifestava, sob a forma de suspeições e de embargos, opiniões e interesses que lutavam entre si. Assim, a câmara atendia à opinião pública, ao que se murmurava e dizia nas ruas, evitando o ajuntamento de pessoas, a fim de que não se divulgassem as ocorrências das reuniões das vereações e de que não se dessem, pois, motivos para protestos (SOARES, 1999, p. 121).

Desse modo, esses estudos têm ampliadoa discussão e a análise sobre o poder municipal, tanto na esfera legislativa como executiva, e têm apontado que o governo municipal não pode ser entendido como um bloco monolítico, ou seja, os estudos tradicionais sobre o Estado consagraram as câmaras municipais como órgãos político-administrativos anulados pela subordinação aos poderes central e regional. Portanto, em trabalhos mais recentes, essas instituições aparecem como dotadas de uma dinâmica e interesses políticos específicos, além de deterem alguma margem de autonomia no governo da cidade, na qual são capazes de influir decisivamente nas políticas de saúde e higiene pública, ordenamento do espaço urbano, organização da economia local e disciplinamento dos indivíduos na sociedade. Ou seja, as câmaras municipais passaram a ter o poder de normatizar o espaço urbano, de policiar e disciplinar a população com o intuito de tornar o meio urbano um espaço mais "limpo", ordeiro e organizado.

\section{Para Figueiredo,}

[...] a prática de lançar tributos conforme foi praticada no Rio de Janeiro e Bahia para cobrir gastos com a defesa abriu um significativo precedente na política fiscal ao possibilitar às Câmaras um direito apenas dos reis (1996, p. 446-451).

Há que se destacar, portanto, o caráter sustentativo, ou até mesmo autônomo, de algumas câmaras municipais no Brasil. O fato dessas, além da simples administração dos impostos criados pela metrópole, lançarem, por sua conta, taxas e arrecadações e de administrar contratos, demonstra certa tendência ao autogoverno (BICALHO, 1998). Tarcísio Botelho e Patrícia Abdo também afirmam que

[...] era através das Câmaras que o município era dirigido, possibilitando ao povo aplicar o privilégio de autogovernar-se, na medida em que elegiam seus próprios representantes, administrando, assim, a sua vila e seus interesses (2008, p. 25).

Porém, a historiadora Avanete Sousa acredita que

[...] uma possível autonomia camarária não significaria, necessariamente, autogoverno. A autonomia de ação identificada dava-se no interior do sistema, e não fora dos ditames monárquicos. Ao contrário, a câmara atuava de forma a fazer que as diretrizes régias confluíssem para o horizonte dos seus próprios interesses (2005, p. 321, grifo da autora).

Ainda de acordo com a historiadora, "os procedimentos práticos do poder local calcavam-se em autonomia de ação, que era delegada, permitida, e, em muitos casos, até mesmo incentivada [...]" (2005, p. 321, grifo da autora). As rendas da câmara eram constituídas, principalmente, do arrendamento 
do direito de exploração de seus bens e serviços públicos e da vistoria do uso de pesos e medidas, mas podia dispor de dois terços do valor recolhido, sendo o restante repassado à Fazenda Real (MIRANDA, 2000, p. 50).

Por tudo isso, as câmaras municipais eram responsáveis em delegar algumas funções, entre elas, mencionamos: supervisionar a distribuição e o arrendamento das terras municipais, lançar e coletar impostos municipais, fixar os preços de muitas mercadorias e provisões, conceder licença a vendedores ambulantes, aos comerciantes e aos taverneiros (aqueles que não a tinham eram multados pelos juízes almotacés, segundo as posturas municipais - elaboradas pela própria câmara -, tornando-se uma fonte de renda para ela), estabelecer regras sobre o uso de pesos e medidas padronizados, verificar a qualidade do que era vendido, conceder licenças e supervisionar as construções, assegurar a manutenção de estradas e pontes, cadeias e outras obras públicas, regular a saúde e o saneamento público, garantir a segurança e o policiamento da cidade, e combater a ação de intermediários (BOXER, 2002; SILVA, 2006; SOUSA, 2009). Para que a câmara fosse responsável e pudesse pôr em prática todas essas funções, haveria de ter funcionários encarregados de aplicar tais medidas e, entre eles, estão os juízes almotacés, nomeados pela câmara municipal, que eram responsáveis pela fiscalização de tudo que dizia respeito ao abastecimento e ao comércio de alimentos, bem como ao ordenamento do espaço urbano, passando pela saúde e higiene pública do município. ${ }^{2}$

\section{A câmara municipal de Rio Pardo}

Da mesma forma que a historiografia brasileira negligenciou, por algum tempo, os estudos a respeito dos poderes locais - e municipais e, principalmente, sobre as câmaras municipais, a historiografia gaúcha também pouco valorizou a história dessas instituições. Apesar da tardia colonização lusitana no Rio Grande do Sul e, por conseguinte, da instalação das referidas câmaras no período colonial, poucos estudos foram feitos sobre essa instituição. Trabalhos como o de Adriano Comissoli sobre a Câmara Municipal de Porto Alegre, o de Fábio Kuhn sobre a Câmara de Viamão, e o de Carina Martiny sobre a Câmara de São Sebastião do Caí, são alguns dos estudos recentes voltados às câmaras municipais, a seu funcionamento e às relações que ocorreram nesse universo camarário (KÜHN, 2006; COMISSOLI, 2008; MARTINY, 2010).

Estudos recentes destacam a importância dessas instituições de poder local, evidenciando a centralidade dos cargos camarários, não apenas como espaço de hierarquização e distinção dos indivíduos, mas também como espaço de negociação com a Coroa. Nesse sentido, ser membro da câmara transformava os ocupantes desses cargos em "cidadãos", habilitados a participar do governo político do Império, colocando-os numa situação privilegiada para fazer uso dos recursos do conselho. Além disso,

[...] as elites locais procuravam os cargos municipais mais pelo prestígio social que deles retiravam do que por vantagens financeiras. É certo que não recebiam ordenados, mas as propinas ou emolumentos não seriam de desprezar (SILVA, 2005, p. 143). 
Conforme explicitado, dentre os órgãos que faziam parte da administração portuguesa na América, as câmaras municipais constituíram-se em um dos mais importantes. Lidavam com as questões do dia a dia da população e, durante o período em que foram o centro da administração municipal, essas eram responsáveis pela organização, normatização e normalização da vila. Além disso, eram responsáveis por fazer cumprir os códigos de posturas e organizar o espaço social urbano. Da mesma forma que tinham a incumbência de controlar as finanças e a vida municipal, eram responsáveis pelo pagamento das pessoas que cuidavam e criavam os enjeitados ou expostos, ${ }^{3}$ bem como lhes competia proceder ao pagamento dos ordenados dos seus funcionários, ao pagamento do conserto de uma ponte, da reforma da cadeia, entre outras provisões, feitas pelo tesoureiro da câmara, ${ }^{4}$ fortalecendo a ideia de que essa possuía condições de se autogerir. Podemos enumerar casos que confirmam o domínio das receitas locais pela câmara municipal de Rio Pardo a partir da cobrança de licenças e multas, tais como: "em doze de novembro de mil oitocentos e onze a câmara municipal recebeu a quantia de $4 \$ 200$ réis referentes à licença de lojas e tavernas" ${ }^{5}$

Nesse sentido, mais do que poder, a câmara e seus membros demonstravam e exercitavam sua autoridade perante a sociedade local, visto que passaram a exercer prerrogativas que lidavam no dia a dia do município e dos munícipes, ou seja, as câmaras municipais não exerceram somente funções meramente administrativas, agiam no cotidiano e em contato direto com a população. O corpo administrativo da Câmara Mu- nicipal de Rio Pardo era eleito, assim como em todas as outras câmaras municipais na colônia, pelo sistema de pelouro. Os eleitos eram notificados e cada um deveria solicitar junto ao juiz municipal sua Carta de Usança, sem a qual não poderiam tomar posse no cargo para o qual tivessem sido escolhidos. ${ }^{6}$

Em 20 de maio de 1811, a câmara municipal é criada e a Vila de Rio Pardo é oficialmente instalada. Da mesma forma, realizou-se a eleição, por parte do "povo" e da "nobreza" da terra, dos indivíduos que ocupariam o cargo de eleitor. Estes, por sua vez, indicaram os nomes dos indivíduos que fizeram parte do processo de eleição para os oficiais camarários. Pelo sistema de pelouro, elegeram-se dois juízes ordinários, três vereadores e um procurador, e, posteriormente, a câmara elegeria os demais oficiais que compunham a instituição, como juiz de órfãos, escrivães, tesoureiro e juízes almotacés.

\section{Aqueles que tinham o poder de disciplinar a sociedade e normatizar 0 espaço urbano}

Ao mesmo tempo em que se elegiam os indivíduos que ocupariam os principais cargos da câmara, estes nomeavam outros oficiais, entre eles, os juízes almotacés. Para a Vila de Rio Pardo, a nomeação dos juízes almotacés era realizada aos pares, e estes atuariam no local e em seu termo por um período de três meses, sendo responsáveis, como especificado anteriormente, por normatizar e disciplinar a vida urbana. Na Câmara de Rio Pardo, passava a provisão a oito almotacés no ano, nos períodos do início do mês 
de janeiro até março, abril a junho, julho até setembro e outubro a dezembro, podendo haver reeleição para mais de um mandato. "Aos sete dias do mês de julho de mil oitocentos e vinte e quatro, nesta vereança se deu posse e juramento ao capitão Manoel Baptista de Mello a ao alferes Manoel Pereira Vianna para servir ao cargo de juiz almotacé nesta Villa nos meses de julho, agosto e setembro".? Abaixo, reproduzimos o modelo do termo de juramento e posse dos juízes almotacés:

Termo de juramento e posse aos Almotacés

Aos três dias do mês de julho de mil oitocentos e onze anos nesta Villa de Rio Pardo em casas da Câmara achando-se presentes o juiz presidente e mais oficiais dela e os almotacés eleitos o sargento-mor Jose Joaquim de Figueiredo Neves e Francisco da Silva Bacellar aos quais o dito juiz presidente [...] o juramento dos santos evangelhos em um livro em que puseram as suas mãos direitas se lhes encarregou que bem e fielmente servirem seus ofícios para que tenham sido eleitos guardando em tudo o serviço de deus e do príncipe regente... $\mathrm{E}$ sendo por eles definidos os seus juramentos assim o prometerem fazer e logo o dito juiz os ouve por empossados e para constar mandou lavrar este termo em que assinam o juiz e os ditos empossados. ${ }^{8}$

As posturas municipais eram o principal instrumento que possibilitava às câmaras municipais ordenar os aspectos do cotidiano das municipalidades, servindo de base para o desenvolvimento do ofício de almotacé. Cabia a essas leis estabelecer os padrões a serem seguidos em Rio Pardo, com o intuito de disciplinar a população e normatizar o espaço urbano. E, quanto ao cargo de almotacé, este deveria instrumentalizar tais normas, fazer a vigilância da vila, o discipli- namento da população e a normatização do espaço urbano. Ou seja, essas determinações foram introduzidas no Brasil de forma adaptada, e as posturas da Câmara de Rio Pardo confirmavam as normas centrais das Ordenações Filipinas, acrescentando ordens que eram específicas da localidade.

Dessa maneira, para a municipalidade, o ofício de juiz almotacé tornou-se vital porque era através dele que as normas e determinações da câmara eram cumpridas e que as posturas eram postas em prática. Uma dessas práticas e responsabilidade era evitar que a população fosse enganada pelos comerciantes, na pesagem ou no preço dos alimentos, uma vez que a câmara regulava o preço dos alimentos e o juiz almotacé fiscalizava-os. Ainda em relação à aplicabilidade das posturas, caso os indivíduos não estivessem de acordo com essas normas, seriam multados, e o valor dos pagamentos e o recolhimento das multas aplicadas pelos juízes aos infratores eram destinados à câmara, na forma de receita para o município. $\mathrm{O}$ valor das multas estava estipulado nas posturas e dependia do tipo de infração cometido pelo indivíduo. Nesse sentido, ao estabelecer um valor para multa, o código atribuía um preço à obediência.

Logo, a concepção de punição aponta para a ideia de prevenção, ou seja, a pena como um mal positivo e deve ser corrigido na forma da prevenção. Os códigos de posturas assumem, portanto, uma modelo correlacional, preventivo da ordem e da segurança pública, um conjunto de normas que estabeleciam regras de comportamento e convívio de uma determinada comunidade e sociedade, portanto, assumem também uma 
esfera normativa. A penalidade na forma de multas tinha por função não ser somente uma resposta à infração, mas, de certa maneira, corrigir os indivíduos ao nível de seus comportamentos, de suas atitudes, de suas disposições, do perigo que representavam à sociedade, moldando padrões de conduta que garantissem o equilíbrio da vida urbana (SCHMACHTENBERG, 2004; WEBER, 1992). Ainda, era de responsabilidade dos juízes almotacés a aplicabilidade das posturas municipais, dessas normativas com o intuito de garantir a ordem e o convívio social.

$\mathrm{O}$ valor arrecadado pelas condenações e multas era destinado aos "cofres" municipais, auxiliando na própria receita do município, receita essa que, conforme Antônio Manoel Hespanha, fazia com que as câmaras tivessem certo prestígio frente ao poder régio, uma vez que a detenção de uma receita própria por parte desses órgãos tornava-os capazes de arcar com as próprias despesas (HESPANHA, 1994). No capítulo 28 do livro de correições dos almotacés, encontra-se a menção de que os valores das multas aplicadas por eles seriam destinados às obras públicas do município: "Proveu que as coimas, que eles como juízes privativos delas devem conhecer fossem todas aplicadas para as obras públicas do conselho, com declarações que as condenações nunca excederão as quantias taxadas e estabelecidas pelas posturas". ${ }^{9}$

Nesse contexto, há que se enfatizar que grande parte das multas foi aplicada a comerciantes estabelecidos na Vila de Rio Pardo. Entre os motivos mais comuns para a aplicação das correições, citam-se o mau estado de conservação dos estabelecimentos comer- ciais; a não aferição da balança e dos pesos e medidas; a tentativa de ludibriar os juízes, fechando a porta de seus mercados enquanto os almotacés faziam a corrida; a falta de licença da câmara para abrir seu comércio e exercer as suas atividades. ${ }^{10}$ Isso demonstra que a câmara procurava manter um rígido controle dessas atividades comerciais e do estado de conservação dos estabelecimentos. Nesse sentido, as condenações e multas aplicadas estavam em consonância com o que determinavam as posturas e o regimento dos almotacés, indo de encontro aos interesses da câmara municipal de proteger a integridade, o bem-estar e a saúde da população.

Como tais punições eram frequentes e recorrentes, busca-se demonstrar que os donos dos estabelecimentos comerciais negavam a ordem e a moral imposta pelas normas camarárias (BOTELHO; ABDO, 2008), até porque as Ordenações Filipinas definiam que os juízes almotacés que atuassem nos meses de janeiro e julho de cada ano mandariam anunciar, em cada um dos meses mencionados, os que tivessem medidas ou pesos por reduzir. Ou seja, os donos dos estabelecimentos comerciais tinham conhecimento de que as corridas e correições ocorreriam e, mesmo assim, desrespeitavam as normas, um desvio de conduta e uma resistência à ordem. Portanto, a fiscalização em relação aos pesos e medidas no que diz respeito às atividades comerciais, era uma forma de poder que a câmara municipal tinha com intuito de garantir a ordem nas relações de mercado e punir aqueles que desrespeitavam as normas.

Além disso, demostra também a preocupação da câmara e dos próprios juízes almotacés em relação à saúde pública da vila, 
principalmente com a qualidade dos gêneros alimentícios; o tabelamento dos preços; com os pesos e medidas, para que, de certa forma, os moradores da vila não fossem prejudicados ou enganados na hora de comprar suas mercadorias. ${ }^{11}$ Para tanto, fazia-se a aferição das balanças, dos pesos e medidas, conforme determinado pelas posturas municipais, e todo aquele comerciante que tivesse com os pesos, as medidas e balanças aferidas e regularizadas do seu estabelecimento, receberiam uma licença da câmara para comercializar seus produtos, cuja revisão desses seria feita nas casas dos almotacés. ${ }^{12} \mathrm{~A}$ fiscalização minuciosa dos mecanismos de medidas e pesos, que eram usados nesses estabelecimentos, reforçava, segundo Lemes, ao estudar a dinâmica da Câmara Municipal na Capitania de Goiás, "o poder da câmara no sentido de manutenção da ordem nas relações de mercado" (LEMES, 2005, p. 183), o que se aplica também para a Vila de Rio Pardo.

Cumpre destacar que os juízes almotacés dirigiam-se à câmara e, em audiência, faziam o relato das corridas e correições que tinham realizado, para, em seguida, repassar ao tesoureiro da casa o valor das multas aplicadas. É importante ressaltar um dado significativo: as corridas e as correições não tinham uma regularidade, ou seja, existia um intervalo de vários dias entre uma e outra. Já quanto às audiências, realizadas na câmara municipal, estas ocorriam com frequência, quando a câmara se reunia, duas vezes por semana, às quartas-feiras e aos sábados. Nesses dias, o juiz almotacé apresentava-se (na câmara) e relatava se havia, ou não, feito alguma correição e condenação. Em função disso, percebe-se a importante conexão entre a câmara municipal e a almotaçaria e, nesse sentido, embora frequentes opiniões afirmem que as câmaras municipais perderam seu poder político no século XVIII, percebemos, nesse caso, que a Câmara Municipal de Rio Pardo exerceu sua autonomia política, sua autonomia da ação (SOUSA, 2005), o poder de administrar a municipalidade e suas receitas, principalmente a partir de uma diretriz régia, a almotaçaria, exercendo o controle dos espaços urbanos, da atividade comercial, do cotidiano e do modo de agir da população, disciplinando e regulando a vida em sociedade.

Na medida em que os juízes almotacés saíam para realizar as corridas e as correições, eram acompanhados e auxiliados pelo escrivão da almotaçaria, que fazia os registros e as anotações de toda a movimentação e fiscalização realizada. Essas anotações eram utilizadas pelo almotacé quando esse se apresentasse à câmara e fizesse a audiência de correição, como especificado. Isso era importante para que a câmara pudesse atestar o cumprimento e a aplicação da lei, bem como para que pudesse registrar a entrada do valor das multas cobradas pelos almotacés.

Da mesma forma que o juiz almotacé deveria comparecer à câmara e fazer a audiência, os infratores deveriam fazer o mesmo, comparecendo em audiência à câmara, perante o escrivão da almotaçaria, e fazer o pagamento de suas multas. Somente após esse pagamento, o infrator seria absolvido de sua condenação. Assim, "compareceu em audiência à câmara, no dia dezoito de julho de mil oitocentos e onze, João Rodrigues Bahia, para fazer o pagamento de sua condenação, 
uma multa no valor de um mil e seiscentos réis, referente a quatro bezerros que foram apanhados na vila". ${ }^{13}$ Cumpriu a pena, pagando a multa. Percebemos, portanto, que a aplicação das posturas e das próprias penalidades representava algo concreto, que era aplicado, ou seja, a partir desse registro observa-se que os infratores realmente pagavam as multas impostas a eles.

Além disso, a aglomeração de pessoas nos estabelecimentos comerciais e tavernas eram proibidas pelas posturas municipais. ${ }^{14}$ Todo dono de comércio ou taverna que permitisse "ajuntamento" de pessoas, especialmente escravos, seriam multados. Havia uma expressa determinação na lei para que os juízes almotacés condenassem os donos de estabelecimentos comerciais caso esses permitissem a presença de negros em seus recintos sem a devida licença e autorização. O comerciante João Rodrigues Bahia condenado a pagar uma multa de seiscentos réis por "consentir ajuntamento de negros" em seu estabelecimento. ${ }^{15}$ Verifica-se, portanto, uma clara tentativa de controle social por parte da câmara municipal, de normatizar e disciplinar os indivíduos que circulavam pela vila. Botelho e Abdo afirmam que a "aglomeração de negros e mulatos nas tavernas era uma associação perigosa e poderia gerar intranquilidade e desordem a sociedade local" (2008, p. 32).

Denise Moura, ao analisar a movediça e tumultuada cidade de São Paulo, entre 1808 e 1850, afirma que as "vendas e tabernas eram locais de ebulição social por misturar os segmentos sociais em contatos provisórios, de origens e destinos distintos." Destaca também que "o que acontecia den- tro de vendas e tabernas era visto pelas autoridades municipais e policiais como 'corrupção da moral pública' e favorecimento de roubos e crimes". A partir dessa classificação, as autoridades

[...] reuniam argumentos necessários para legislar sobre estes espaços, solicitando o aumento do valor das avenças como meio de frear sua multiplicação ou cobrando separadamente as casas (MOURA, 2005, p. 192-193).

Nesse sentido, para manter um equilíbrio fundamental à vida urbana, buscando evitar ou contornar situações que poderiam conduzir a um intolerável prejuízo à moral e ao sossego da Vila de Rio Pardo, fazia-se necessário uma constante vigilância por parte dos juízes almotacés, algo previsto nas normativas e determinações dos códigos de posturas municipais. Assim, o poder de administrar a localidade materializava-se no também secular direito de almotaçaria, exercido pelos juízes almotacés, que deveriam periodicamente, realizar a fiscalização, averiguando o cumprimento das posturas e vereações municipais no que tangia as atividades comerciais, ao construtivo, à higiene sanitária e a outras questões de ordenamento urbano, disciplinando a população e normatizando o espaço urbano.

Por tudo isso, percebe-se o poder que o juiz almotacé possuía por consentimento da câmara e da comunidade, em controlar e disciplinar os moradores e as atividades comerciais, isto é, seu poder e sua atribuição lhe garantiam e permitiam agir em prol da população, na fiscalização do cotidiano da vila. Assim, assumia a função de juiz mediador e arbitrava certas sentenças. Através do seu 
julgamento, eram estabelecidas as normas justas para o funcionamento das atividades cotidianas, assegurando, desse modo, um clima ordeiro e de tranquilidade, em que as relações sociais deveriam prevalecer na busca pelo bem comum e pelo direito de igualdade de todos os moradores da Vila de Rio Pardo.

Dessa forma, além de fiscalizar e policiar as atividades comerciais, vigiar e disciplinar a população, zelar pelo bem-estar da saúde pública da vila, observar e fazer cumprir as determinações e dispositivos das construções e edificações, a ação da almotaçaria também constituía uma espécie de juizado de "pequenas causas", a que recorriam os moradores da Vila quando surgisse alguma desavença motivada por questões de uso do espaço, construção de moradias e limpeza, causando prejuízo, principalmente, aos vizinhos. Percebe-se, nesse caso, que os almotacés adquiriam outra função no universo do construtivo, não somente a de vigiar construções e edificações, mas também a de mediar conflitos vicinais. ${ }^{16}$

Nos casos envolvendo querelas entre os moradores da vila, os juízes almotacés atuavam como mediadores e eram os primeiros representantes da autoridade municipal a fazerem vistorias no local, acionando a justiça caso não houvesse acordo. Inicialmente, os moradores tentavam resolver as disputas particulares de forma autônoma, sem a mediação e interferência de nenhuma autoridade municipal ou judicial. Não havendo um consenso, uma reconciliação entre as partes e não resolvendo conseguindo resolver o problema, recorriam aos juízes almotacés e, caso esses não conseguissem amenizar a disputa, pondo a ela um pon- to final, o processo era julgado pelo juiz de vintena, ${ }^{17}$ menor instância do poder judiciário em atuação. Por isso, destacamos que o próprio juiz de vintena, em certos casos, ordenava a intervenção dos juízes almotacés nessas disputas.

Acredita-se que a maior parte dos conflitos envolvendo os moradores da localidade de Rio Pardo era provocada por problemas causados por divisão de muros, colocação de cercas e disputas por terrenos, os quais, inicialmente, deveriam ser resolvidos entre os próprios moradores. Caso isso não ocorresse e não havendo consenso, entraria a autoridade dos juízes almotacés como mediadora, em uma tentativa de evitar a abertura de processo na justiça. Nesse sentido, o juiz almotacé assumiu a função de mediar e julgar pequenas causas, uma espécie de juizado envolvendo os moradores da vila, dispondo de poder e autoridade para condenar e administrar aos culpados sanções ou multas.

Mesmo assim, pouco fala-se sobre a ação mediadora que os almotacés tiveram em algumas vilas brasileiras. A sua ação era direcionada a fiscalizar e a vigiar o espaço e ordenamento urbano, a atividade comercial e a higiene das vilas. Em Rio Pardo, nas primeiras décadas do século XIX, os juízes almotacés, além das atribuições elencadas, tinham o objetivo a resolução de pequenos conflitos entre os moradores. Essa ação, definida pela legislação, concedia ao almotacé o poder de justiça, de julgar e resolver conflitos entre os moradores da vila, constituindo-se uma primeira instância do poder judiciário dentro da câmara municipal, antes mesmo do juiz de vintena. 
Segundo Enes,

[...] a justiça, normalmente por seus oficiais da vintena, ordenava intervenções de qualquer natureza, com obras de muros ou paredes pelos moradores, os almotacés eram acionados ao findar tais obras para verificar se as mesmas tinham ocorrido a contento (2010, p. 90).

Porém, em muitos casos, o almotacé era chamado para solucionar o conflito, penalizando e condenando o réu ou, algumas vezes, condenando ambas as partes envolvidas. Desse modo, determinamos tal ação como uma instância do poder judicial dentro da câmara municipal, o qual dava ao juiz almotacé poder de deliberar e tomar decisões, que de certa forma, ampliavam sua área de atuação e responsabilidade, de decidir quem era culpado ou inocente dentro de uma ação cível ou criminal de juízo e de multar o condenado. Nesse sentido, essas ações evidenciam a preocupação da almotaçaria em resolver problemas relacionados à concentração humana e os males que isso poderia provocar à vila, atuando diretamente no convívio social, ampliando sua esfera de atuação para além das questões urbanísticas, sanitária e comercial.

Assim, o juiz almotacé percorria toda a Vila de Rio Pardo, ordenando, normatizando e regulamentando-a até que sua autoridade fosse reconhecida. Controlar o tráfego de animais, a circulação de moradores e forasteiros, observar a higiene das habitações e dos alimentos, dos estabelecimentos comerciais, mediar as rivalidades e disputas entre moradores da vila e seu termo, regularizar as fachadas das edificações urbanas, a estética das casas, da medição dos terrenos e a própria morfologia urbana da vila faziam parte de suas atribuições. A atuação pontual dos juízes almotacés em resolver certos conflitos e problemas envolvendo os moradores sinalizava uma atitude que visava dar à sociedade e às relações sociais um caráter civilizador, condicionando a vila ao desenvolvimento urbano e ao seu crescimento. Ao exigir da população local o cumprimento das normas e posturas municipais quanto à limpeza e à higiene, ao ordenamento urbano, os almotacés incutiam uma urbanidade, mesmo que a posteriori, uma forma de civilidade aos moradores da Vila de Rio Pardo (NICOLAZZI Jr., 2003, p. 81).

Portanto, não apenas as preocupações com a forma urbana, com o aspecto da vila, com as questões de ordem higiênica e comercial faziam parte da matéria de atuação dos juízes almotacés, mas a manutenção de toda uma ordem moral e social, envolvendo os moradores da vila e que deveria funcionar adequadamente. Nesse sentido, a sociedade, a estrutura urbana da vila de um modo geral e o bem-estar social da população deveriam ser zelados na busca por uma ordem civilizatória, em uma importante região da Província do Rio Grande de São Pedro como era a Vila de Rio Pardo. Dessa forma, a busca incessante para resolver os problemas e os conflitos entre os moradores da vila, envolvendo a fiscalização do correto cumprimento das posturas, levou os juízes almotacés a atuarem até a extinção de seu cargo, em 1828. 


\section{Abstract}

Social History and Political History studies accomplished since the nineties have made use of municipal documents with the objective of reconstructing different aspects of the city everyday life. In approaching problems related to issues such as housing, health and public hygiene and trade, these studies have emphasized not only the everyday life, but also the powers that control everyday life and the ones that control the life and the society in the villages and in the cities. Therefore, this paper analyses the power and the performance of the Town Hall of Nossa Senhora do Rio Pardo Village and of the almotacés judges in the first decades of the XIX century, as a way of ruling social life, controlling and disciplining citizens, trade activities, health and public hygiene and housing, presenting a perspective that emphasizes that Town Halls had the power of self government and that they were not merely institutions subordinated to central and regional powers.

Keywords: Art to govern. Local power. Town hall.

\section{Resumen}

Los estudios realizados a partir de la década de 1990, en el campo de la Historia Social y de la Historia Política, han recurrido a la documentación producida en el ámbito municipal con el objetivo de reconstruir diferentes aspectos de lo cotidiano de la ciudad. Al abordar los problemas relacionados a las cuestiones como vivenda, salud, higiene pública y comercio, esos estudios han enfatizado no solamente la vida cotidiana, pero también los poderes que controlan ese cotidiano, que controlan la vida y la sociedad en las villas y en las ciudades. Por lo tanto, este texto analiza el poder de la Cámara Municipal de la Villa de Nuestra Señora de Rio Pardo y la actuación de los jueces almotacés en las primeras décadas del siglo XIX, como forma de regular la vida social, controlando y disciplinando a los ciudadanos, las atividades y establecimientos comerciales, la salud, la higiene pública y la viviendas.

Palabras clave: Arte de gobernar. Poder local. Municipalidad.

\section{Notas}

1 Este artigo é parte integrante de minha tese de doutorado intitulada $A$ arte de governar: redes de poder e relações familiares entre os juízes almotacés na Câmara Municipal de Rio Pardo/RS, 1811 - c.1830, defendida no Programa de Pós-Graduação em História da Universidade do Vale do Rio dos Sinos.

2 Os juízes almotacés eram funcionários da câmara municipal responsáveis em fazer as corridas e correições na vila. Inspecionavam e fiscalizavam, principalmente, os estabelecimentos comerciais para verificar o seu estado de higiene e verificar também se os comerciantes não vendiam mercadorias adulteradas à população. Além disso, eram responsáveis por cuidar da higiene e da saúde pública da vila.

3 "Mandamos ao tesoureiro deste conselho, Francisco Silveira Gomes, em virtude de mandado por nós assinado, pagar a Ignácio da Silva Nogueira a quantia de quatorze mil e quatrocentos reis de nove meses de criação da enjeitada Carlota, vencidos em quinze de fevereiro do corrente ano, dando a competente quitação. Rio Pardo, em vereança, 03 de março de 1819". Códice Geral da Câmara Municipal de Rio Pardo, CG n ${ }^{\circ} 08,1819$, p. 56. Rio Pardo, Arquivo Histórico do Município de Rio Pardo (AHMRP). 
4 "Mandamos o tesoureiro do conselho, Francisco Silveira Gomes, o pagamento ao porteiro dos Auditórios desta vila, Manoel da Paixão, a quantia de sete mil e quinhentos reis de seu ordenado vencido. Rio Pardo em vereança, 19 de abril de 1822". Códice Geral da Câmara Municipal de Rio Pardo, CG n ${ }^{\circ} 11,1822$, p. 85. Rio Pardo, AHMRP.

5 Livro de receita e despesas da câmara municipal. Livro $n^{\circ} 277$ - 1811. Rio Pardo, AHMRP.

6 Registro de uma carta de usança de Juiz Ordinário do Tenente José Martins da Cruz. Livro de Registros Gerais da Câmara de Rio Pardo. Livro $\mathrm{n}^{\circ} 01$ - 1811. Rio Pardo, AHMRP.

7 Livro de Atas da Câmara Municipal de Rio Pardo. Livro no 02 - 1827/1829. Rio Pardo: AHMRP.

8 Livro de Posses e Juramentos da Câmara Municipal de Rio Pardo. Livro n ${ }^{\circ} 02$ - 1811/1847. Rio Pardo, AHMRP.

9 Livro de registros da almotaçaria - capítulos de correição. Livro no 01 - 1811/1823. Rio Pardo: AHMRP. Coimas eram as multas aplicadas pelos juízes.

10 Livro de Registro da Almotaçaria. Livros no 05 e 06 - 1811/1828. Rio Pardo, AHMRP. João Rodrigues Bahia foi condenado, pelos juízes almotacés José Joaquim de Figueiredo Neves e Francisco da Silva Bacellar a pagar uma multa de $2 \$ 000$ réis por não ter sua taverna com asseio de vida. O comerciante Albino Francisco do Bem foi condenado, pelos almotacés Nicolau Ferreira Jardim e Joaquim José da Fonseca e Souza Pinto a pagar uma multa de $3 \$ 000$ réis pelo dolo e malícia de fechar a sua venda na ocasião que ia passando a corrida. Bento Rodrigues Seixas foi condenado, pelos almotacés João Rodrigues Palhares e João de Sá Brito a pagar uma multa no valor de $2 \$ 000$ réis por ter sua loja de fazenda seca aberta sem licença.

11 Estas preocupações constam nos artigos de $\mathrm{n}^{\mathrm{o}}$ 11 ao $\mathrm{n}^{\circ} 24$ das Posturas Municipais. Livro de Registros das Posturas Municipais. Livro n 02 1811/1824. Rio Pardo, AHMRP.

12 Livro de Registros das Posturas Municipais. Livro $N^{\circ} 02$ - 1811/1824. Art. 19. Rio Pardo, AHMRP.

13 Livro de Registros da Almotaçaria. Livro no 02 1811/1845. Rio Pardo, AHMRP.

14 "Acordaram que os taverneiros não consintam nas suas tavernas, escravos parados, comendo, jogando ou conversando, com pena de dois mil réis pela primeira vez, pela segunda vez quatro mil réis, pagos da cadeia e pela terceira e mais vezes serão condenados em seis mil réis e trinta dias de cadeia sendo aplicada a terça parte da pena para a vereança, ou a quem denunciar, ou ao oficial que fizer a diligência sem denúncia e as duas terças partes aplicadas para o conselho". Livro de Registros das Posturas Municipais. Livro $n^{\circ} 02$ - 1811/1824. Rio Pardo, AHMRP.

15 Livro de Registros da Almotaçaria. Livro ${ }^{\circ} 05$ e 06 - 1811/1828. Rio Pardo, AHMRP.

16 Pequenos conflitos envolvendo familiares ou vizinhos, motivados, principalmente, por disputas de áreas de terras. (PEREIRA, 2001, p. 12; NICOLAZZI Jr., 2003, p. 74).

17 Eleitos anualmente pelos juízes, procurador e vereadores da Câmara. Suas atribuições: conhecer e decidir, verbalmente, sobre as contendas entre os moradores de sua jurisdição, até a quantia de no máximo quatrocentos réis, sem apelação e agravo nem abrir processo (SALGADO, 1985, p. 131).

\section{Referências}

BICALHO, Maria Fernanda. As câmaras municipais no império português: o exemplo do Rio de Janeiro. Revista Brasileira de História. São Paulo, v. 18, n. 36, 1998.

BOTELHO, Tarcísio Rodrigues; ABDO, Patrícia Ferraz. Administração camarária e comércio na Vila Rica do século XVIII: os almotacés e as correições, 1754-1777. Revista Caminhos da História. Universidade Estadual de Montes Claros, Montes Claros, MG, v. 13, n. 2, 2008.

BOXER, Charles. O império maritimo português: 1415-1825. São Paulo: Companhia das Letras, 2002.

COELHO, Maria Helena da Cruz. A história e a historiografia municipal portuguesa. CAPELA, José V (Coord.). O município português na história, na cultura e no desenvolvimento regional. Braga: Projecto PRAXIS XXI, Compolito, 1999. COMISSOLI, Adriano. Os "homens bons" e a câmara municipal de Porto Alegre (1767-1808). Porto Alegre: Coleção Teses e Dissertações, v. 1, Câmara Municipal de Porto Alegre, 2008.

ENES, Thiago. De como administrar cidades $e$ governar impérios: almotaçaria portuguesa, os mineiros e o poder (1745-1808). 2010. Dissertação (Mestrado em História) - Programa de Pós-graduação em História, Universidade Federal Fluminense, Rio de Janeiro, 2010. 
FIGUEIREDO, Luciano R. de A. Revoltas, fiscalidade e identidade colonial na América portuguesa. Rio de Janeiro, Bahia e Minas Gerais (16401761). 1996. Tese (Doutorado em História) Programa de Pós-Graduação em História, Universidade de São Paulo, São Paulo, 1996.

HESPANHA, António Manoel. As vésperas do Leviathan: instituições e poder politico, Portugal século XVII. Coimbra: Livraria Almedina, 1994.

KÜHN, Fábio. Gente da fronteira: família, sociedade e poder no sul da América Portuguesa - século XVIII. 2006. Tese (Doutorado em História, Programa de Pós-graduação em História, Universidade Federal Fluminense, Rio de Janeiro, 2006.

LEMES, Fernando Lobo. A oeste do império dinâmica da câmara municipal na última periferia colonial: um estudo das relações de poder nas Minas e Capitania de Goiás (1770-1804). 2005. Dissertação (Mestrado em História) - Programa de Pós-graduação em História - Universidade Federal de Goiás, Goiânia, 2005.

MARTINY, Carina. "Os seus serviços públicos e políticos estão de certo modo ligados à prosperidade do município": constituindo redes e consolidando o poder: uma elite política local (São Sebastião do Caí, 1875-1900). 2010. Dissertação (Mestrado em História) Programa de Pós-graduação em História, Universidade do Vale do Rio dos Sinos, São Leopoldo, 2010.

MIRANDA, Márcia Eckert. Continente de São Pedro: a administração pública no período colonial. Porto Alegre: Assembléia Legislativa do Estado do RS; Ministério Público do Estado do RS; CORAG, 2000.

MOURA, Denise A. Soares de. Sociedade movediça: economia, cultura e relações sociais em São Paulo, 1808-1850. São Paulo: Ed. UNESP, 2005.

NICOLAZZI Jr, Norton Frehese. O Almotacé na Curitiba colonial (1718-1828). In: PEREIRA, Magnus Roberto de Mello; NICOLAZZI Jr., Norton Frehese (Orgs.). Audiências e correições dos Almotacés (Curitiba, 1737 a 1828). Curitiba: Aos Quatro Ventos, 2003.
PEREIRA, Magnus Roberto de Mello. Almuthasib - Considerações sobre o direito de almotaçaria nas cidades de Portugal e suas colônias. Revista Brasileira de História. São Paulo, v. 21, n. 42, 2001.

PEREIRA, Magnus Roberto de Mello; NICOLAZZI, Norton Frehse (Orgs.). Audiências e correições dos Almotacés (Curitiba, 1737 a 1828). Curitiba: Aos Quatro Ventos, 2003.

RUSSEL-WOOD, A. J. R. Fidalgos e filantropos. A Santa Casa de Misericórdia da Bahia (15501755). Brasília: EdUNB, 1981.

SALGADO, Graça (Coord.). Fiscais e meirinhos: a administração no Brasil colonial. 2. ed. Rio de Janeiro: Ed. Nova Fronteira, 1985.

SANTOS, Antônio Cesar de Almeida; SANTOS, Rosângela Maria Ferreira dos. (Orgs.). Eleições da Câmara Municipal de Curitiba (1748 a 1827). Curitiba: Aos Quatro Ventos, 2003.

SCHMACHTENBERG, Ricardo. A saúde pública e o processo de modernização do espaço urbano de Santa Cruz do Sul na república velha. 2004. Dissertação (Mestrado em História) Programa de Pós-Graduação em História, Universidade do Vale do Rio dos Sinos, São Leopoldo, RS, 2004.

SCHWARTZ, Stuart B. Burocracia e sociedade no Brasil colonial: o tribunal superior da Bahia e seus desembargadores, 1609-1751. São Paulo: Companhia das Letras, 2011.

SILVA, Isis Messias de. Legislação portuguesa e formação de elites políticas locais: a câmara municipal de Curitiba no século XVIII. In: PEREIRA, Magnus R. de M.; SANTOS, Antônio C. de A.; ANDREAZZA, Maria L.; NADALIN, Sergio Odilon (Orgs.). (Ed.). VI JORNADA SETECENTISTA: CONFERÊNCIAS E COMUNICAÇÕES, 6,. Curitiba: Aos Quatro Ventos, CEDOPE, 2006.

SILVA, Maria Beatriz Nizza da. Ser nobre na colônia. São Paulo: Ed. UNESP, 2005.

SOARES, Sérgio Cunha. A câmara de Coimbra e a Universidade nos séculos XVII e XVIII. In: CAPELA, José V (Coord.). O município português na história, na cultura e no desenvolvimento regional. Braga: Projecto PRAXIS XXI, Compolito, 1999. 
SOUSA, Avanete Pereira. Poder local e autonomia camarária no antigo regime: o senado da câmara da Bahia (século XVIII). In: BICALHO, Maria Fernanda; FERLINI, Vera Lúcia Amaral (Orgs.). Modos de governar: idéias e práticas políticas no império português - séculos XVI-XIX. São Paulo: Alameda, 2005.

Manifestações locais da crise do antigo sistema colonial? (O exemplo das câmaras municipais da capitania da Bahia). In: SOUZA, Laura de Mello e.; FURTADO, Junia Ferreira; BICALHO, Maria Fernanda (Orgs.). O governo dos povos. São Paulo: Alameda, 2009.

SOUZA, Laura de Mello e. Política e administração colonial: problemas e perspectivas. In: SOUZA, Laura de Mello e.; FURTADO, Junia Ferreira; BICALHO, Maria Fernanda (Orgs.). O governo dos povos. São Paulo: Alameda, 2009.

WEBER, Beatriz Teixeira. Códigos de posturas e regulamentação do convívio social em Porto Alegre no século XIX. 1992. Dissertação ( Mestrado em História). Programa de Pós-Graduação em História, Universidade Federal do Rio Grande do Sul, Porto Alegre, 1992. 